\title{
Prevalence of tobacco use among adult and adolescent females in Egypt
}

\author{
F. El Awa, ${ }^{1}$ H. Fouad, ${ }^{1}$ R.A. El Naga, ${ }^{1}$ A.H. Emam ${ }^{2}$ and S. Labib ${ }^{3}$
}

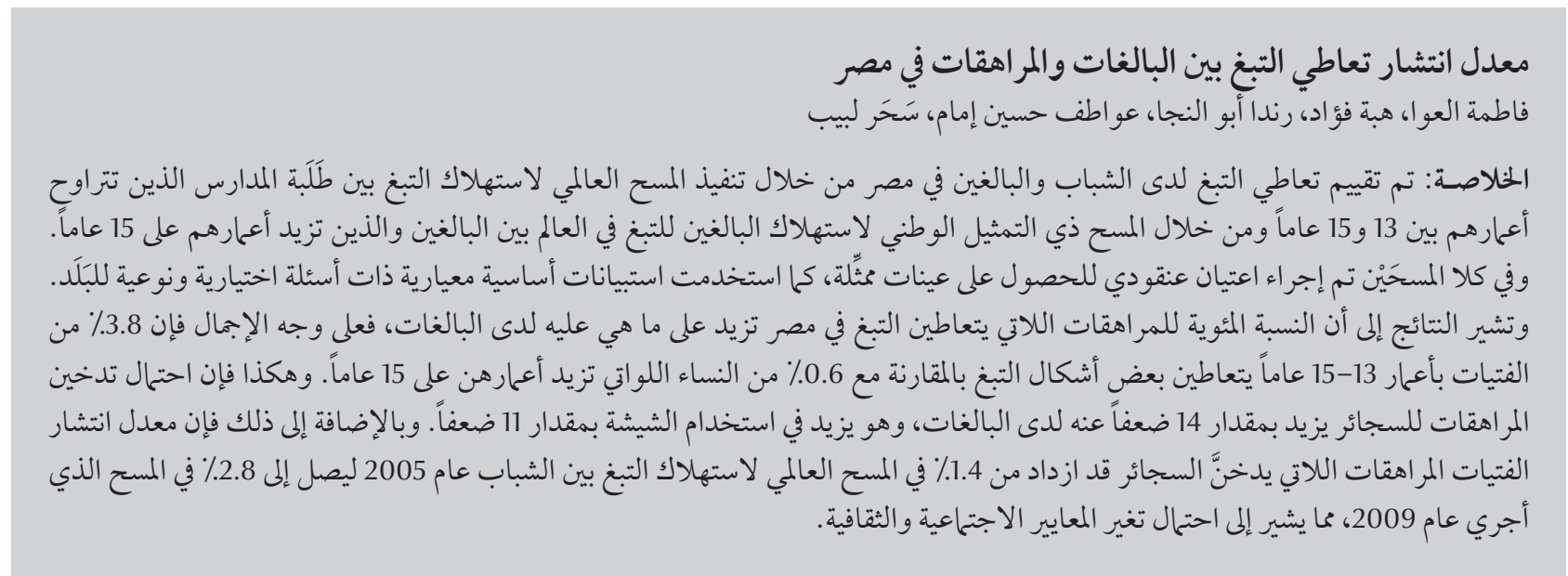

ABSTRACT Egypt assessed tobacco use among young people and adults through implementation in 2009 of the Global Youth Tobacco Survey (GYTS) among school students aged 13-15 years and the nationally representative Global Adult Tobacco Survey (GATS) among adults aged 15+ years. Both surveys employed cluster sampling to produce nationally representative samples and used standard core questionnaires with optional, country-specific questions. The results indicated that a higher percentage of adolescent girls in Egypt used tobacco than did adult females. Overall, 3.8\% of girls aged 13-15 years used some form of tobacco compared with $0.6 \%$ of women aged $15+$ years. Adolescents were over 14 times more likely than adult women to currently smoke cigarettes and 11 times more likely to smoke waterpipes. Moreover, the prevalence of cigarette smoking among adolescent girls had increased from $1.4 \%$ in the 2005 GYTS to $2.8 \%$ in 2009, indicating that social and cultural norms may be changing.

\section{Prévalence de la consommation de tabac chez les femmes adultes et les adolescentes en Égypte}

RÉSUMÉ L'Égypte a évalué la consommation de tabac chez les jeunes et les adultes au moyen de la mise en œuvre en 2009 de l'Enquête mondiale sur le tabagisme chez les jeunes auprès des élèves âgés de 13 à 15 ans et del'Enquête mondiale surle tabagisme chez les adultes, représentative au niveau national, auprès d'adultes de plus de 15 ans. Les deux enquêtes ont eu recours à des échantillonnages en grappes afin de générer des échantillons représentatifs au niveau national et ont administré des questionnaires de base normalisés complétés par des questions optionnelles spécifiques aux pays. Les résultats ont indiqué qu'en Égypte, le pourcentage de consommatrices de tabac était plus élevé chez les adolescentes que chez les femmes adultes. Globalement, 3,8 \% des adolescentes âgées de 13 à 15 ans consommaient du tabac contre 0,6 \% des femmes de plus de 15 ans. Les adolescentes étaient 14 fois plus susceptibles de fumer des cigarettes et 11 fois plus susceptibles de fumer la pipe à eau que les femmes adultes. En outre, la prévalence de la consommation de cigarettes chez les adolescentes a augmenté, passant de 1,4 \% selon les résultats de l'enquête mondiale sur le tabagisme chez les jeunes de 2005 à 2,8 \% en 2009, ce qui indique que les normes sociales et culturelles pourraient être en train de changer.

${ }^{7}$ World Health Organization Regional Office for the Eastern Mediterranean, Cairo, Egypt (Correspondence to F. El Awa: elawaf@who.int). ${ }^{2}$ Central Agency for Public Mobilization and Statistics, Cairo, Egypt.

${ }^{3}$ Ministry of Health, Cairo, Egypt.

Received: 14/05/12; accepted: 06/12/12 


\section{Introduction}

Tobacco use by females is a serious, growing problem throughout the world [1-4]. This was recognized in 1999 by the international health community in the first World Health Organization (WHO) international conference on women and tobacco [1] and in the WHO Framework Convention on Tobacco Control in 2003 [2]. In the Eastern Mediterranean Region (EMR), the prevalence of tobacco use among adult females lags behind that of adult males [4]. Nevertheless, the accruing social changes in some countries of EMR have contributed to an increased acceptance of female smoking especially among the younger generations; this will pave the way for a greater future increase in the prevalence of tobacco use among females [5]. The Global Tobacco Surveillance System data revealed that tobacco use among adolescent females in the EMR was increasing faster for other tobacco products (waterpipe and smokeless tobacco) than for cigarettes. Data from the Global Youth Tobacco Survey (GYTS) between 1999 and 2008 showed that the EMR has the highest prevalence of use of other tobacco products by adolescent females (9\%) compared with the overall average of the $6 \mathrm{WHO}$ Regions (8\%) [6]. The highest rates of use of tobacco products other than cigarettes were found in Lebanon (> 30\%), Jordan, Occupied Palestinian Territory (West Bank), Syrian Arab Republic and United Arab Emirates (> 20\%) [6].

In Egypt, previous studies conducted among adult females have shown that the prevalence of smoking was not high; the prevalence of current smoking or use any form of tobacco in 2005 among ever-married females aged 15-49 years old was reported to be $0.6 \%$ and in 2006 the prevalence of daily tobacco smoking among adult females ages $15-65$ years was $0.7 \%[7,8]$. However, the prevalence of smoking among adolescent females was higher than among adult females. In Egypt, the 2005 GYTS data indicated that $1.4 \%$ of adolescent females aged $13-15$ years old were currently smoking cigarettes, indicating that social and cultural barriers may be changing $[6,9]$.

Egypt assessed tobacco use among both young people and adults through the GYTS and the nationally representative Global Adult Tobacco Survey (GATS) for the first time in 2009. Data from both surveys are considered as the latest available findings on the national prevalence of tobacco use among females in the country. This article reports the difference in the pattern of tobacco use among adolescents and adult females in Egypt in the 2009 surveys.

\section{Methods}

\section{Global Youth Tobacco Survey Sampling}

The 2009 Egypt GYTS was a crosssectional, school-based survey with a 2-stage cluster sampling design to produce a nationally representative sample of students in middle grades 1,2 and 3, which are grades that correspond with students aged 13-15 years. The GYTS was conducted during the 2009 scholastic year. The percentage of girl students enrolled in middle grades was $48 \%$ for grade 1 and $49 \%$ for each of grade 2 and 3 . In the first stage, the sampling frame consisted of all schools (public and private) covering all the governorates in metropolitan cities, north (lower) Egypt and south (upper) Egypt. The probability of schools being selected was proportional to the number of students enrolled in the specified grades. At the second sampling stage, classes within the selected schools were randomly selected. All students in the selected classes were eligible to participate; student participation was voluntary and anonymous.

\section{Data collection}

The anonymous, self-administered GYTS questionnaire was developed by the WHO, the United States Centers for Disease Control and Prevention (CDC) and the Canadian Public Health Association. The 2009 Egypt GYTS used the standard survey questionnaire, consisting of a core component (used in all countries) and an optional component that included additional questions on waterpipe (shisha) smoking. It collected data on: demographics; prevalence of tobacco use; knowledge and attitudes regarding tobacco; exposure to secondhand smoke; exposure to pro- and anti-smoking media and advertising; smoking cessation; and the school curriculum addressing tobacco use. All of the items had been used in previous rounds of GYTS and had been evaluated for reliability and validity.

A weighting factor was used to reflect the likelihood of sampling each student and to reduce bias by compensating for differing patterns of nonresponse. Epi Info was used to compute 95\% confidence intervals ( $\mathrm{CI}$ ) for the estimates.

\section{GYTS response rate}

A total of 4796 students (including 2530 girl students) completed the 2009 Egypt GYTS from 39 sampled schools who participated in the survey. The overall response rate was $97.1 \%$. The school response rate was $100 \%$, the class response rate was $100 \%$ and the student response rate was $97.1 \%$.

\section{Global Adult Tobacco Survey Sampling}

The 2009 Egypt GATS was a household survey designed to produce national level estimates of indicators of interest by sex, age group, education and region. A multistage, geographically clustered sample was used to achieve a national representative sample of adult males and females aged 15 years and older from 5 regions that covered all Egyptian governorates. GATS covered the 
metropolitan governorates (Cairo, Alexandria, Suez and Port Said), as well as governorates in lower and upper Egypt. Participating households were chosen randomly within a sampling unit.

\section{Data collection}

GATS data collection was made through face-to-face interviews and recorded on handheld machines. Interviews were conducted in all selected households; 1 eligible individual 15+ years old was selected randomly within each selected household. The GATS data collection took place from midMarch until the end of May 2009.

As for the GYTS, the 2009 Egypt GATS used the standard survey questionnaire consisting of a standard core component and a country-specific optional component with additional questions. The questionnaire was developed by the $\mathrm{WHO}$ and the CDC to provide a global standard protocol for consistent monitoring of adult tobacco use [10].

The GATS questionnaire has 2 parts: the household questionnaire and the individual questionnaire. The questions on the household questionnaire asked about: the number of household members; the number of eligible respondents; and then the age, sex and current tobacco use of each eligible respondent in the household. The individual questionnaire had 8 sections which covered the following topics: tobacco prevalence and consumption pattern; tobacco smoking and smokeless tobacco use; cessation; exposure to secondhand smoke; prices and taxation; exposure to pro- and anti-smoking media and advertising; and knowledge, attitudes and perceptions towards tobacco use. In Egypt, countryspecific questions included items about waterpipe smoking [10].

Complex survey data analysis was performed to obtain population estimates and 95\% CI. Sample weights were used to account for the complex survey design and to produce nationally representative estimates. Computations of estimates and confidence intervals were performed using SPSS, version 17 complex samples module.

\section{GATS response rate}

The total number of completed interviews was 20946 (including 10069 males and 10877 females) with a weighted population estimate of $49.1 \%$ females and $50.9 \%$ males. The overall individual response rate was $98.1 \%$. The household response rate was $98.9 \%$ and the individual response rate was $98.4 \%$.

\section{Results}

\section{Tobacco use}

The GATS data revealed that an overall percentage of $0.6 \%$ of adult females aged $15+$ years in Egypt reported use of some form of tobacco product, while the GYTS data showed that adolescent females reported tobacco use at a higher rate than adult women. An overall percentage of $3.8 \%$ of 13-15-year-old girls used some form of tobacco (Table 1).

\section{Prevalence of cigarette smoking}

In the GATS data $0.2 \%$ of females aged $15+$ years reported that they smoked cigarettes. A higher rate of cigarette smoking was seen among adult females from metropolitan areas $(0.9 \%)$. The GYTS data showed that the overall rate of current cigarette smoking among adolescent females aged 13-15 years was higher (2.8\%) compared with adult females. Moreover, the reported prevalence of current cigarette smoking was higher $(4.7 \%)$ among adolescent females 13-15 years old living in metropolitan areas compared with adults (Table 1).

\begin{tabular}{|c|c|c|c|c|}
\hline \multirow[t]{3}{*}{ Group } & \multirow{3}{*}{$\begin{array}{c}\text { Use of any tobacco } \\
\text { product } \\
\%(95 \% \mathrm{Cl})\end{array}$} & \multicolumn{3}{|c|}{ Prevalence of current use ${ }^{c}$} \\
\hline & & Cigarettes & Waterpipe & Smokeless tobacco \\
\hline & & $\%(95 \% \mathrm{Cl})$ & $\%(95 \% \mathrm{Cl})$ & $\%(95 \% \mathrm{Cl})$ \\
\hline \multicolumn{5}{|c|}{ Adolescent girls 13-15 years ${ }^{a}$} \\
\hline Overall (national) & $3.8(2.2-6.5)$ & $2.8(1.2-6.3)$ & $3.4(1.8-6.5)$ & $\mathrm{n} / \mathrm{a}$ \\
\hline Metropolitan & $4.8(2.0-11.2)$ & $4.7(1.8-11.5)$ & $4.4(1.5-12.2)$ & $\mathrm{n} / \mathrm{a}$ \\
\hline Lower Egypt & $2.9(0.9-8.4)$ & $0.4(0.1-1.4)$ & $2.4(0.7-7.9)$ & $\mathrm{n} / \mathrm{a}$ \\
\hline Upper Egypt & $2.8(1.2-6.5)$ & $1.3(0.3-4.5)$ & $2.4(1.1-5.2)$ & $\mathrm{n} / \mathrm{a}$ \\
\hline \multicolumn{5}{|c|}{ Adult females $15+$ years $^{b}$} \\
\hline Overall (national) & $0.6(0.4-0.9)$ & $0.2(0.1-0.4)$ & $0.3(0.2-0.6)$ & $0.3(0.2-0.5)$ \\
\hline Metropolitan & $1.0(0.6-1.7)$ & $0.9(0.5-1.5)$ & $0.1(0.0-0.3)$ & $0.5(0.2-0.9)$ \\
\hline Lower Egypt & $0.1(0.1-0.3)$ & $0.1(0.0-0.2)$ & $0.1(0.0-0.2)$ & 0.0 \\
\hline Upper Egypt & $1.0(0.6-1.8)$ & $0.1(0.0-0.2)$ & $0.7(0.3-1.5)$ & $0.5(0.2-0.9)$ \\
\hline
\end{tabular}

${ }^{a}$ Source: Global Youth Tobacco Survey, 2009. Denominator: 2530 girl students; ${ }^{b}$ Source: Global Adult Tobacco Survey, 2009. Denominator: 10 877 females; ${ }^{c}$ Current use includes both daily and occasional (less than daily) use.

$C l=$ confidence interval; $n / a=$ question not asked. 


\begin{tabular}{|c|c|c|c|}
\hline \multicolumn{4}{|c|}{$\begin{array}{l}\text { Table } 2 \text { Current use of tobacco products among adult Egyptian females aged 15+ years by age group and educational level, } \\
\text { Egypt, } 2009\end{array}$} \\
\hline \multirow[t]{2}{*}{ Variable } & $\begin{array}{l}\text { Current use of any tobacco } \\
\text { product }^{\mathrm{b}}\end{array}$ & Current cigarette smoking ${ }^{c}$ & $\begin{array}{l}\text { Current waterpipe } \\
\text { smoking }\end{array}$ \\
\hline & $\%(95 \% \mathrm{Cl})$ & $\%(95 \% \mathrm{Cl})$ & $\%(95 \% \mathrm{Cl})$ \\
\hline \multicolumn{4}{|l|}{ Age group (years) } \\
\hline $15-24$ & $0.2(0.1-0.6)$ & $0.1(0.0-0.3)$ & $0.1(0.0-0.5)$ \\
\hline $25-44$ & $0.5(0.3-0.7)$ & $0.3(0.2-0.5)$ & $0.1(0.1-0.3)$ \\
\hline $45-64$ & $1.4(0.9-2.2)$ & $0.5(0.2-1.0)$ & $0.6(0.3-1.3)$ \\
\hline $65+$ & $1.7(0.8-3.3)$ & 0.0 & $1.4(0.7-3.1)$ \\
\hline \multicolumn{4}{|l|}{ Education level ${ }^{a}$} \\
\hline No formal & $1.1(0.6-1.8)$ & $0.2(0.1-0.4)$ & $0.7(0.3-1.4)$ \\
\hline Some primary & $1.1(0.6-2.0)$ & $0.4(0.1-1.3)$ & $0.4(0.2-1.2)$ \\
\hline$\geq$ primary $/<$ secondary & $0.3(0.1-0.8)$ & $0.3(0.1-0.8)$ & 0.0 \\
\hline Completed secondary & 0.0 & 0.0 & 0.0 \\
\hline Diploma & $0.1(0.0-0.5)$ & $0.1(0.0-0.4)$ & 0.0 \\
\hline$\geq$ University & $0.6(0.2-1.6)$ & $0.5(0.2-1.6)$ & 0.0 \\
\hline
\end{tabular}

${ }^{a}$ Education level: no formal = no formal education; some primary = attended but not finished primary school; $\geq$ primary/ $<$ secondary = completed primary school, attended but not finished preparatory school, completed preparatory school, or attended but not finished high school; completed sec =completed high school/ equivalent education $: \geq$ university = completed university/college or postgraduate degree obtained .

${ }^{b}$ Current use includes both daily and occasional (less than daily) use; 'Cigarettes includes manufactured and handrolled cigarettes. Source: Global Adult Tobacco Survey, 2009. Denominator: 10877 females.

\section{Prevalence of waterpipe use}

The GATS data showed that $0.3 \%$ of adult females reported smoking waterpipes. The highest level of waterpipe use among adult females was seen in upper Egypt $(0.7 \%)$ compared with other regions $(0.1 \%)$. Data from the GYTS, however, showed that waterpipe smoking among adolescent females was much higher, with an overall rate of $3.4 \%$. A higher rate of waterpipe smoking was found among adolescent females living in metropolitan areas (4.4\%) compared with upper and lower Egypt (both 2.4\%) (Table 1).

\section{Prevalence of smokeless tobacco use}

The GATS data revealed for the first time that smokeless tobacco was used among adult females at the same rate as waterpipe smoking $(0.3 \%)$. A similar finding was noted among adult females using smokeless tobacco and living in upper Egypt and metropolitan areas (0.5\%) (Table 1). Data on smokeless tobacco use were not available from the GYTS for adolescent females.

\section{Prevalence of tobacco use by age and education}

Table 2 shows the 2009 GATS data for current use of cigarettes and waterpipes among adult females by age group and educational level. The prevalence of use of tobacco products rose with increasing age from $0.2 \%$ at age $15-24$ years to $1.7 \%$ at age $65+$ years. Waterpipe smoking was more prevalent among the lowest educational group (0.7\%) than the higher levels, while cigarette use increased with educational level from $0.2 \%$ among women with no education to $0.5 \%$ among university educated women.

\section{Discussion}

The data reported here demonstrate the current status of the tobacco epidemic among adult and adolescent females in Egypt. Comparisons with earlier GATS and GYTS data (discussed below) suggest that tobacco use is a rising health problem among adolescent Egyptian females in comparison with assessments conducted a few years earlier and in comparison with a concurrent assessment of adult women.

The GATS data for 2009 revealed that cigarettes and the waterpipe were the most common type of tobacco smoked by adult women, followed by smokeless tobacco. GATS Egypt is the only large-scale nationally representative survey to provide comprehensive tobacco use estimates by interviewing a sample of 10877 respondent adult women. Results from GATS Egypt were consistent with other previous surveys conducted in Egypt. The 2009 GATS found that $0.6 \%$ of women aged $15+$ years used some form of tobacco. The 2005 Demographic and Health Survey (DHS) also reported that $0.6 \%$ of ever-married women aged 15-49 years old were tobacco smokers [7] and the 2008 DHS found that $0.4 \%$ of females of the same age group smoked cigarettes and $0.2 \%$ used other forms of tobacco (waterpipe was the most common form of other tobacco used) [11].

Nevertheless, the results showed that the prevalence of cigarette and waterpipe smoking among adult females ( $0.2 \%$ and $0.3 \%$ respectively) still lags 
far behind the prevalence for males who constitute the majority of tobacco consumers among adult Egyptians [4]. Data for tobacco use among males reported in GATS 2009 an overall level of $37.9 \%$ compared with $0.6 \%$ among women. Almost one-third of men (31.8\%) were current smokers of cigarettes, men were more likely than women to smoke waterpipes $(6.2 \%$ versus $0.3 \%)$ and they currently used smokeless tobacco at higher rates than did women ( $4.8 \%$ versus $0.3 \%$ ) [12].

Similarly, the prevalence of current smoking of any tobacco product among women is low in many of the EMR countries. Data reported by WHO in 2008 showed that rates reached as low as $0.2 \%$ in Morocco, $1 \%$ in Oman, $3 \%$ in Iraq and Sudan, 4\% in Saudi Arabia and Kuwait and 5\% in the Islamic Republic of Iran [4]. WHO has suggested that this low prevalence is due to social traditions and women's low economic resources rather than to health awareness [5].

The GYTS data for 2009 showed that, although the prevalence of tobacco use among female students in Egypt was less than $5 \%$, young girls were over 14 times more likely than adult women to currently smoke cigarettes and 11 times more likely to smoke waterpipes. Moreover, earlier results from the GYTS revealed that the prevalence of young girls smoking cigarettes had almost doubled over the last 4 years; from $1.4 \%$ in 2005 to $2.8 \%$ in 2009 , indicating that social and cultural norms may be changing $[6,9]$. In recent years, an increase in the number of waterpipe smokers among young girls has been noted in urban areas, especially among those of higher socioeconomic class and higher educational level [13]. In the 2005 GYTS the data for waterpipe smoking were included in the category "other tobacco products", so the data could not be compared directly with the 2009 study.

Despite the relatively low rate of tobacco use by women, it is expected that tobacco use among women will increase in developing countries in view of changing cultural norms, women's increased spending power and tobacco industry activities targeting females [1]. This phenomenon may be reflected in the relatively high prevalence of tobacco use among young girls aged $13-15$ years in some countries of the EMR; rates of tobacco use among this age group have reached as high as $19.5 \%$ in the Islamic Republic of Iran, 26.8\% in the Syrian Arab Republic, 27.7\% in the Occupied Palestinian Territory (West Bank) and $54.1 \%$ in Lebanon [14].

On analysing the prevalence among different adult female groups, it was found that those with university level of education or higher had a higher prevalence of cigarette consumption. This can be attributed to the well-established linkage in consumers' minds between smoking and a more liberated feminine identity promoted by tobacco companies' marketing campaigns for women $[3,5]$. Social factors may play a signifcant role in the higher use of waterpipes among adult females residing in upper Egypt for whom greater affordability and old traditions may permit waterpipe use by women.

GATS 2009 revealed the use of smokeless tobacco by women in Egypt. For the first time, smokeless tobacco by adult Egyptian females was found to be used at the same level in both metropolitan and upper Egypt regions. This new information necessitates attention and further investigation.

\section{Conclusions and future direction}

Comparing the 2009 GYTS with the 2005 survey provides some evidence supporting the idea that tobacco use among adolescent females in Egypt is increasing (both cigarettes and other tobacco products) especially in metropolitan cities. The findings raise concerns about future trends and highlight the need for more in-depth studies, especially among adult females, to be able to verify the apparent change that is currently taking place in social norms concerning women's smoking.

As observed when comparing the 2009 GATS and GYTS results with those of 2005, the difference between adults and young females is narrowing. This result was anticipated before conducting GATS in Egypt and has now been confirmed by the data [13].

Women used all the tobacco products available in Egypt, including cigarettes, waterpipes and smokeless tobacco. Adult data showed for the first time that smokeless tobacco is consumed by women in some areas of Egypt. In fact, the prevalence of waterpipe use was the same as the prevalence of smokeless tobacco among adult women. Monitoring of smokeless tobacco use needs to include the adolescent age group to determine if use is also extending to adolescent girls.

The findings call for comprehensive tobacco control interventions, to target and control the expected rise of tobacco use among young females, taking into account social and economic changes at the national level. Otherwise, the current prevalence of tobacco use among young girls may become higher.

\section{Acknowledgements}

GATS is a multi-partner initiative of the World Health Organization, US Centers for Disease Control and Prevention, Johns Hopkins Bloomberg School of Public Health, the CDC Foundation. GATS was made possible by: funding from the Bloomberg Initiative to Reduce Tobacco Use, which supported this project throughout its implementation phases; technical support provided by the US Centers for Disease Control and Prevention, Research Triangle International and Johns Hopkins Bloomberg School of Public Health; and programme support provided by the CDC Foundation. The 
implementing agencies were the Egyptian Ministry of Health, Central Agency for Public Mobilization and Statistics and WHO country office.
GYTS is a multi-partner initiative of the World Health Organization, US Centers for Disease Control and Prevention, Canadian Public Health
Association, GYTS was implemented by the Ministry of Health and Population in Egypt.

Competing interests: None declared.

\section{References}

1. Women and the tobacco epidemic: challenges for the 27st century. Geneva, World Health Organization, 2001.

2. WHO Framework convention on tobacco control. Geneva, World Health Organization, 2003.

3. Toll BA, Ling PM. The Virginia Slims identity crisis: an inside look at tobacco industry marketing to women. Tobacco Control, 2005, 14:172-180.

4. Report on the global tobacco epidemic. 2008: the MPOWER package. Geneva, World Health Organization, 2008.

5. Gender and tobacco. Health and gender information sheet series. Cairo, World Health Organization Regional Office for the Eastern Mediterranean, 2005.

6. Warren CW et al. The GTSS atlas. Atlanta, Georgia, CDC Foundation, 2009

7. NCD indicators: Egypt. World Health Organization Global InfoBase [online database] (https://apps.who.int/infobase/ report.aspx, accessed 10 May 2013),

8. El-Zanaty F, Way A. Egypt Demographic and Health Survey 2005. Calverton, Maryland, Ministry of Health and Population (Egypt), National Population Council, El-Zanaty and Associates and Macro International, 2006.

9. El-Awa F, Warren CW, Jones NR. Changes in tobacco use among 13-15-year-olds between 1999 and 2007: findings from the Eastern Mediterranean Region. Eastern Mediterranean Health Journal, 2010, 16:266-273.

10. Global Adult Tobacco Survey Collaborative Group. Global Adult Tobacco Survey: core questionnaire with optional questions, Version 2.0. Atlanta, Georgia, Centers for Disease Control and Prevention, 2010.

11. Zanaty F, Way A. Egypt Demographic and Health Survey 2008. Calverton, Maryland, Ministry of Health and Population (Egypt), National Population Council, El-Zanaty and Associates and Macro International, 2009.

12. Global adult tobacco survey: Egypt country report 2009. Cairo, World Health Organization Regional Office for the Eastern Mediterranean, 2010 (http://www.who.int/tobacco/surveillance/gats_rep_egypt.pdf, accessed 15 July 2013).

13. Comparison of cigarettes and waterpipe smoking among female university students in Egypt. In: Tobacco use in waterpipe: studies on waterpipe smoking in Egypt. Cairo, World Health Organization Regional Office for the Eastern Mediterranean, 2006.

14. Global Youth Tobacco Surveillance, 2000-2007. Surveillance summaries, January 25. Morbidity and Mortality Weekly Report, 2008, 57(No. SS-1):1-56. 